\title{
Do the ward notes reflect the quality of end-of-life care?
}

\author{
Daniel P Sulmasy, Maureen Dwyer and Eric Marx \\ Georgetown University Medical Center, Washington, \\ $D C, U S A$
}

\begin{abstract}
Objectives - To study the accuracy of reviewing ward notes (chart review) as a measure of the quality of care rendered to patients with "Do Not Resuscitate" (DNR) orders.
\end{abstract}

Design - We reviewed the charts of 19 consecutive, competent inpatients with DNR orders for evidence that the staff addressed a broad range of patient care needs called Concurrent Care Concerns (CCCs), such as withholding treatments other than resuscitation itself, and attention to patient comfort needs. We then interviewed the patient, consultant physician, house officer, and primary nurse and compared the ward notes with the understandings of these staff members.

Setting - The medical service of an urban university medical centre.

Results - The average number of documented CCCs addressed per DNR order was 1.1. The ward notes generally agreed with the perceptions of patients, house officers, and nurses (\% agreement with notes $=79 \%$, $77 \%$, and $82 \% ; \kappa=0.43,0.40,0.50)$. Consultant physicians' understandings were poorly reflected in the ward notes ( $\%$ agreement $=59 \% ; \kappa=0 \cdot 18$ ). They overestimated attention to CCCs compared with the notes $(P<0.0001)$ and with other observers ( $P$ $<0.0001)$.

Conclusion - Chart review for attention to CCCs accurately reflects the understandings of patients, house officers, and nurses, but consultant physicians report more attention to CCCs than is recorded in the ward notes or understood by other observers. Better communication regarding end-of-life care plans should be encouraged.

The Patient Self Determination Act of 1990 $(\text { PSDA })^{1}$ was passed in the hope that it might improve the care of the dying in the USA by requiring that all patients be asked, on admission to the hospital, whether they have advance directives (such as living wills) that specify limits on lifesustaining treatments. If patients answer no, they

\section{Key words}

Medical ethics; resuscitation; quality of health care; validity. must be asked whether they would like information about their rights to such documents. Unfortunately, advance directives in general, ${ }^{2}$ and the PSDA in particular, ${ }^{3}$ have had little impact on the quality of end-of- life care.

Regardless of whether the patient has an advance directive, "Do Not Resuscitate" (DNR) orders are often appropriate at the end of life. Ethicists have argued that DNR orders ought to be very clearly and narrowly defined, making it clear that in the event of a full cardiopulmonary arrest no resuscitative measures of any kind are to be undertaken. ${ }^{4-8}$ Yet, patients, consultant physicians, and other caregiverg may have different understandings about what DNR order means. ${ }^{6}$

Although they are not to be resuscitated, patients with DNR orders continue to have many medical needs that ought to be addressed by the staff if good quality care is to be rendered. We have called these the "Concurrent Care Concerns" (CCCs) of patients with DNR orders. These include the clarity with which the scope of the interventions to be withheld has been delimited and whether or not certain comfort needs of these patients have been addressed. These ten CCCs are: whether the patient is to be intubated for respiratory distress short of a full cardiopulmonary arrest; whether the patient is to be dialyzed, receive antibiotics, blood products, or pressor drugs; whether the adequacy of pain control has been addressed, whether discharge to home or hospice has been planned, whether the patient's spiritual needs have been addressed, and whether the patient will receive artificial hydration or $N$ nutrition.

It is important to have a simple, valid method of monitoring the quality of service rendered to these patients. We ${ }^{9}{ }^{10}$ and others, ${ }^{11}{ }^{12}$ have used review of ${ }^{\circ}$ patients' ward notes (chart review) to provide data for this assessment. The major advantage of this method is its relative simplicity. However, we have ? become uncomfortable because this method has never been validated for such an assessment. It has never been definitively shown that chart review accurately reflects the attentiveness of staff to the CCCs 8 of patients, or that the ward notes accurately reflect 2 physicians' and nurses' understanding of how to 


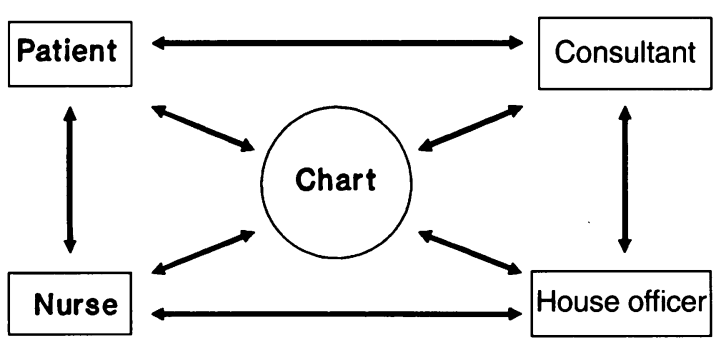

Figure 1 Design: validation by multiple comparisons

proceed in situations short of a full cardiopulmonary arrest. Skeptics might argue, for instance, that the range of treatments to be withheld is often verbally clarified among the professional staff, but simply not recorded in the ward notes.

We have previously developed a method of reviewing ward notes for evidence that the staff have paid attention to these CCCs within 48 hours of writing a DNR order. ${ }^{10}$ We have found that this method is reliable. ${ }^{9}$ Our major objective in this study was to validate how well this chart-review method represents the understandings of the involved parties about whether attention has been paid to CCCs for patients with DNR orders, by comparing a review of the ward notes with the interview responses of patients and staff at a university hospital.

\section{Methods}

This project was approved by the Institutional Review Board of the Georgetown University Medical Center. We studied consecutive, competent, English-speaking medical inpatients for whom DNR orders were written while under the care of full-time faculty in General Internal Medicine, Oncology, or Infectious Diseases at Georgetown University Medical Center during the 1993-1994 academic year. We excluded patients deemed incompetent by their house officers.

Our method of validation is depicted in figure 1 . We reviewed the patients' ward notes for medical and demographic data and documentation of attention to CCCs, using the methods and explicit definitions we have described in more detail elsewhere. ${ }^{9}$ We assessed the validity of our chart review by comparing it with the impressions of the consultant physician, patient, house officer, and nurse. We also compared the impressions of the involved parties with each other. Attention to a CCC was defined as either (A) an explicit decision about each CCC or (B) a discussion among consultant physicians, house officers, or nurses specifically considering each CCC in relation to the patient's plan of care. Agreement was defined as agreement that attention had been paid to each CCC, not as agreement about the content of the decision.

Our structured ten-minute interviews took place between two and five days after the writing of the
DNR order, and were conducted by a single nurseinvestigator, blinded to the study objectives. Questions were closed-ended, with "yes", "no", or "don't know" responses. Each "don't know" response was coded as indicating a lack of attention to that specific CCC according to that observer. Patients were asked about whether they were spoken to about each CCC. Consultant physicians were asked whether they had either spoken to the patient or to the staff about each CCC, or whether they had reached a specific decision regarding each CCC. The patient's primary nurse and junior house officer were asked whether they were aware that the staff had specifically considered each CCC or had reached a specific decision regarding each CCC. The complete instrument is available upon request.

\section{STATISTICAL ANALYSIS}

We used the kappa statistic to study the inter-rater agreement between all sources in multiple pairwise comparisons. We used the McNemar test to assess the significance of the direction of disagreement between raters. Computations were performed using the SPSS/PC software package. ${ }^{13}$

\section{Results}

The study took six months to complete. Sixty-three patients with DNR orders written by eligible faculty were identified. Thirty-five of these patients were? ineligible for the study due to diminished decisionmaking capacity. Nine eligible patients refused to participate, generally citing the severity of their illness. Seven of these nine were women. Nineteen patients gave written, informed consent to be interviewed. All targeted staff members agreed to be interviewed, bringing the total number of patients and staff interviewed to 76 .

The patients we studied were $84 \%$ white and $79 \%$ men. Their average age was 52 . Sixty-eight per cent had cancer and $26 \%$ had AIDS.

Table 1 shows that, with the exception of pain control and sedation, there was little evidence in the ward notes of documentation of attention to CCCs. About a third of patients' ward notes specifically clarified whether DNR also meant "Do Not Intubate". Discharge planning was documented for

Table 1 Per cent reported attention to specific concurrent care concerns (CCCs)

\begin{tabular}{|c|c|c|c|c|c|}
\hline$C C C$ & Chart & Consultant & Patient & Nurse & House officer \\
\hline Intubation & $32 \%$ & $68 \%$ & $50 \%$ & $53 \%$ & $53 \%$ \\
\hline Dialysis & $0 \%$ & $16 \%$ & $11 \%$ & $0 \%$ & $5 \%$ \\
\hline Blood & $0 \%$ & $37 \%$ & $16 \%$ & $22 \%$ & $16 \%$ \\
\hline Antibiotics & $11 \%$ & $68 \%$ & $15 \%$ & $16 \%$ & $37 \%$ \\
\hline Pressors & $11 \%$ & $53 \%$ & $5 \%$ & $16 \%$ & $32 \%$ \\
\hline Pain meds & $90 \%$ & $79 \%$ & $84 \%$ & $63 \%$ & $79 \%$ \\
\hline Discharge & $32 \%$ & $74 \%$ & $68 \%$ & $47 \%$ & $68 \%$ \\
\hline Spiritual & $0 \%$ & $11 \%$ & $16 \%$ & $11 \%$ & $5 \%$ \\
\hline Nutrition & $5 \%$ & $42 \%$ & $11 \%$ & $16 \%$ & $16 \%$ \\
\hline Hydration & $0 \%$ & $32 \%$ & $5 \%$ & $16 \%$ & $16 \%$ \\
\hline
\end{tabular}


Table 2 Kappa scores for overall agreement with ward notes

\begin{tabular}{lccc}
\hline & Consultant physician & Patient & Nurse \\
\hline Per cent agreement & $59 \% \star$ & $80 \%$ & $82 \%$ \\
Kappa (95\% confidence interval) & $0 \cdot 18(0 \cdot 07,0 \cdot 29)$ & $0.44(0 \cdot 30,0 \cdot 46)$ & $0 \cdot 50(0 \cdot 35,0 \cdot 65)$ \\
\hline
\end{tabular}

Figures are based on chart review regarding attention to 10 Concurrent Care Concerns for 19 patients with DNR orders, compared with the understandinghs of members of the health care team as expressed during interviews.

^Significantly less agreement than all others, Chi square $=29.5 \mathrm{P}<0.0001$ ).

Table 3 Attention to concurrent care concerns: agreement between consultant physicians and other sources

\begin{tabular}{lccc}
\hline $\begin{array}{l}\text { Consultant physician } \\
\text { compared with: }\end{array}$ & $\begin{array}{c}\text { Per cent } \\
\text { agreement }\end{array}$ & $\begin{array}{c}\text { Kappa } \\
\text { (95\% confidence interval) }\end{array}$ & $\begin{array}{c}\text { Per cent } \\
\text { overestimation by consultant }\end{array}$ \\
\hline Ward Notes & $59 \%$ & $0 \cdot 18(0 \cdot 07,0 \cdot 29)$ & $30 \%$ \\
Patient & $69 \%$ & $0 \cdot 37(0 \cdot 24,0 \cdot 48)$ & $41 \cdot 8(<0 \cdot 0001)$ \\
Nurse & $58 \%$ & $0 \cdot 15(0 \cdot 01,0 \cdot 29)$ & $20 \%$ \\
House officer & $70 \%$ & $0 \cdot 39(0 \cdot 26,0 \cdot 50)$ & $23 \%$ \\
\hline
\end{tabular}

«Tests the hypothesis that consultant physicians report more attention to concurrent care concerns compared with each source.

$32 \%$. Attention to other concerns was rarely documented in the ward notes. Patients, house officers, and nurses also reported similarly low rates of attention to specific CCCs. As can also be seen in table 1 , consultant physicians generally reported more attention to CCCs than that recorded in the ward notes or reported by other observers. For example, despite the fact that consultant physicians reported $68 \%$ of the time that they had either discussed intubation with the house officers and nurses or had reached a specific decision regarding whether or not the patient was to be intubated, this was recorded in the ward notes only $32 \%$ of the time and was understood to have been discussed or clearly decided upon in the minds of the patient, nurse, and house officer only about $50 \%$ of the time. Similarly, consultant physicians reported specific attention to blood product support $37 \%$ of the time, while this was never written in the ward notes and such attention was rarely known to other observers. Attention to the use of pressors and nutrition followed a similar pattern. Very few observers thought that the spiritual needs of patients had been attended to by the staff, and this was reflected in the ward notes.

We used kappa scores to assess the inter-rater agreement between the ward notes and the understandings of the involved parties. A kappa of +1 indicates complete agreement, while a kappa of 0 indicates agreement compatible with chance alone. As shown in table 2, agreement between the consultant physicians' assessment of their degree of attention to CCCs and that documented in the notes was $59 \%$, yielding a low kappa score of $0 \cdot 18$. This was significantly less than the agreement noted between the ward notes and each of the other observers. The ward notes reflected the understandings of patients, nurses, and house officers with a reasonable degree of accuracy, yielding kappa scores of 0.40 to 0.50 .
As shown in table 3 , the consultant physicians' understanding of the degree of attention to CCCs was in very poor agreement with that of nurses, and in fair to poor agreement with that of patients and house officers. Compared with each of the other parties, consultant physicians consistently reported a higher degree of attention to CCCs. To test the significance of the consultant physicians' tendency to report a higher rate of attention to CCCso compared to other observers, we used the McNemare method. This difference was highly significant for all comparisons by the McNemar test.

We also collected data regarding communication between the consultant physician and the patient. Fifty-six per cent of otherwise eligible patients were incompetent at the time the DNR order was written. Unfortunately, we have no data on the time of onset of the incompetent state. Of those patients who were deemed competent and consented to participate in our interview, only $58 \%$ report having discussed the DNR order with their doctor, even though they were deemed competent by house officers and were capable of participating in our detailed interview about the subject. The consultant physicians reported that they had discussed the issue with the family but not the patient in $21 \%$ of cases. Consultant physicians and patients were in agreement that discussions of CCCs were infrequent (37\% of the time according to consultant physicians and $32 \%$ according to patients). However, $47 \%$ of patients said they would have wanted to have heard some details about these issues but were never given the opportunity.

A check mark indicating that information about advance directives had been given to patients by admissions office clerks in compliance with the PSDA was found on the ward notes of $82 \%$ of patients. Only $47 \%$ of patients had any recollection of receiving such information. Only one of 19 patients' ward notes contained a completed copy of a patient's advance directive. 


\section{Discussion}

Optimal care for patients with DNR orders includes both an explicit formulation of a plan of care that attends to their Concurrent Care Concerns (CCCs) as well as the promulgation of that plan among the house officers and nurses who provide the bedside care. Our results indicate little documentation in ward notes of attention to CCCs and suggest that even if a wide range of treatment options has been addressed verbally by consultant physicians, there is a serious defect in the promulgation of the details of that plan.

\section{CLINICAL MEANING}

Chart review is certainly a much simpler method than conducting interviews or hiring observers. However, our results suggest that chart review is probably not accurate enough to profile individual physicianpatient interactions. None the less, since chart review does seem to represent a reasonable reflection of the care plans of the house officers and nurses (who actually provide most of the bedside care), it would seem that this method measures the effective clinical state of affairs with acceptable accuracy.

The lack of attention to CCCs that we observed is of concern, since it might lead to withholding lifesustaining treatments such as intubation when treatment might be effective and desired. It could also lead to patients receiving these interventions against their wills. Further, this lack of attention could also result in a delay in transfer to a more comfortable setting such as a hospice, or a denial of the timely spiritual support of pastoral ministry.

While we encourage explicit attention to CCCs, this should not be construed to imply that patients should be asked specifically to give informed consent to each CCC, nor should it be construed to imply that the list of CCCs should be read to the patient like a menu. ${ }^{9}$ Attention to any particular CCC may or may not be relevant to a given patient's clinical situation. Patients will vary in the amount of detail they desire to discuss in relation to their care. None the less, some level of attention to most CCCs will be appropriate for most patients.

We did not collect data on the actual care these patients received with respect to each CCC over the course of hospitalisation. It remains possible that the plans reported by consultant physicians were carried out in the actual care of these patients. However, some of these CCCs, such as intubation, are only likely to become issues in an emergency, in which case it would be quite unlikely for the consultant physicians to be present to direct care. For other CCCs, such as attention to spiritual needs or discharge planning, any delay at all could be considered a deficiency in quality.

\section{EXPLAINING THE DISPARITIES}

The fact that consultant physicians report higher levels of attention to these CCCs than that recorded in the ward notes or known to other observers must be explained. Some might argue that it is still possible that specific decisions were reached by the consultant physician and discussed with the house staff and nurses, but that these conversations were simply forgotten by the other parties. While poor memory might be a plausible explanation with respect to these very sick patients, it does not seem a credible explanation for the disparity between the impressions of consultant physicians and those of the house staff and nurses. It is also important to bear in mind that the other observers were asked to state their own understandings about what aspects of concurrent care had been specifically addressed. They were not asked to corroborate the discussion between the consultant physician and the patient. In any event, the content of all decisions regarding CCCs ought to be communicated to the staff. Not knowing whether to provide pressors for a patient who has become hypotensive, but has not yet had a full cardiopulmonary arrest, can lead to serious clinical confusion.

It is possible that this disparity between the understandings of the consultant physicians and the understandings gleaned from the patients, the staff, and the ward notes is an artifact of the interview technique. During the interview, consultano physicians may have rapidly clarified and made explicit decisions that had been hazy in their owf minds or only implicit before the interview? However, if this were the case, it would suggest that consultant physicians were overestimating their actual attention to CCCs and this would imply that the lack of attention recorded in the ward notes was accurate.

\section{COMMUNICATION BETWEEN CONSULTANT}

PHYSICIANS AND PATIENTS

We do not have data to help sort out whether the difference between consultant physicians and patients was due to a lack of disclosure on the part of the consultant physician, inadequate disclosure to patients who were capable of understanding, failure of these patients later to recall information that was adequately disclosed and comprehended at the time, or subtle mental status deficits that prohibited adequate patient comprehension at the time of the discussion. This calls for further study.

Most of the patients who were otherwise eligible for this study had impaired decision-making capacity at the time the DNR order was written and were therefore excluded. Some of those who were considered competent and who consented to our interview reported that they were never spoken with about their DNR order. In some instances, families were spoken with instead. And a majority of those patients who were spoken with about the DNR order were never spoken with about CCCs. Many of these reported that they would have wanted the 0 opportunity. Other studies have shown that most 
incompetent acutely ill patients were competent just two weeks before hospitalisation, ${ }^{14}$ and that DNR orders are often written just before death. Further, compliance with the requirements of the $\mathrm{PSDA}^{1}$ did not facilitate adequate communication in our study sample. Together, these findings suggest that better methods of encouraging earlier and more effective communication between consultant physicians, patients, and staff regarding these issues ought to be investigated. ${ }^{15}$

Given our small sample size and the fact that this study was performed at a single institution, further corroboration of these findings is warranted.

\section{Conclusions}

We conclude that chart review reasonably reflects a lack of attention to CCCs as understood by patients, nurses, and house officers caring for patients with DNR orders. Consultant physicians report addressing a broader range of treatment options than that reported by other parties or recorded in the ward notes. This suggests that chart review is a reasonably accurate method for monitoring these circumscribed aspects of the quality of care delivered to patients with DNR orders in the aggregate. The method is probably not accurate enough to monitor the practices of individual health care professionals, but this would seem inconsequential since such monitoring would raise serious ethical issues of its own.

The most important implication of the study is that if the consultant physician has considered and reached specific decisions about what is to be done for these patients across a broad range of treatment options, the consultant's plan needs to be communicated to the rest of the staff. The ward notes remain an efficient means of effecting this communication. Efforts to accomplish a clearer understanding of the scope of DNR orders through education ${ }^{9}$ or specific order pages ${ }^{11} 12$ ought to be pursued. The old Chief of Service's adage remains true: "Not charted, not done".

\section{Acknowledgments}

Dr Sulmasy's work was supported by an American College of Physicians' Teaching and Research Scholarship. We are grateful to Drs Kevin Schulman and Edmund Pellegrino for their comments on this manuscript.

Daniel P Sulmasy, OFM, MD, PhD, is Associate Director of the Center for Clinical Bioethics at the Georgetown University Medical Center, Washington, $D C$, USA. Maureen Dwyer, RN, DNSc, is Assistant Professor of Nursing at the University of
Cincinnati. And Eric Marx, MTS, is a Research Associate at the Center for Clinical Bioethics, Georgetown University Medical Center.

\section{References}

1 US Congress. Omnibus Budget Reconciliation Act of 1990. Pub L No. 101-508.

2 Danis M, Southerland LI, Garrett JM, et al. A prospective study of advance directives for life-sustaining care. New England Fournal of Medicine 1991; 324: 882-8.

3 Silverman HJ, Tuma P, Schaeffer $M H$, Singh B. Implementation of the Patient Self Determination Act in a hospital setting. Archives of Internal Medicine 1995; 155: 502-10.

4 The Hastings Center Project on the Termination of Treatment and the Care of the Dying. Guidelines for the termination of life-sustaining treatment and the care of the dying. Bloomington, Indiana: Indiana University Press, 1987: 48-51.

5 Council on Ethical and Judicial Affairs of the American Medical Association. Guidelines for the appropriate use of do-not resuscitate orders. Fournal of the American Medical Association 1991; 265: 1868-1871.

6 Lo B. Unanswered questions about DNR orders. Fournal of the American Medical Association 1991; 265: 1874-5.

7 Ross JW, Pugh D. Limited resuscitation: the ethics of partial codes. Quality Review Bulletin 1988; Jan: 4-8.

8 The President's Commission for the Study of Ethical Problems in Medicine and Biomedical and Behaviorat Research. Deciding to forego life-sustaining treatment. Washington, DC: US Government Printing Office, 1983.

9 Sulmasy DP, Terry PB, Faden R, Levine DM. Long term effects of ethics education on the quality of care for patients with do-not-resuscitate orders. Fournal of General Internal Medicine 1994; 9: 539-543.

10 Sulmasy DP, Geller G, Levine DM, Faden R. The quality of mercy: caring for patients with 'do not resuscitate' orders. Fournal of the American Medical Association 1992; 267: 682-6.

11 O'Toole EE, Youngner, SJ, Juknialis BW, Daly B, Bartlett ET, Landefeld SC. Evaluation of a treatment limitation policy with a specific treatment-limiting order page. Archives of Internal Medicine 1994; 154: 425-432.

12 Mittelberger JA, Lo B, Martin D, Uhlmann R. Impact of a procedure-specific do not resuscitate order form on documentation of do not resuscitate orders. Archives of Internal Medicine 1993: 153: 228-232.

13 Norusis MJ/SPSS, Inc. SPSS/PC+ Base system user's guide. Chicago, Illinois: SPSS, 1992.

14 Wenger NS, Oye RK, Bellamy PE, et al. Prior capacity of patients lacking decision making capacity early in hospitalization. Fournal of General Internal Medicine 1994; 9: 539-543.

15 Jonsson PV, McNamee M, Campion EW. The 'do not resuscitate' order: a profile of its changing use. Archives of Internal Medicine 1988; 148: 2373-5.

16 Glisson K, Wise S. The do-not-resuscitate order: still too little too late. Archives of Internal Medicine 1990; 150: $1057-1060$. 